Open Access

Original Article

\title{
Frequency of iron deficiency anemia (IDA) among patients with Helicobacter pylori infection
}

\author{
Adeel Rahat ${ }^{1}$, Lubna Kamani ${ }^{2}$
}

\begin{abstract}
Background and Objective: Helicobacter Pylori ( $H$. pylori) is a widespread infection across the globe having a high prevalence among the developing countries. Iron Deficiency is anticipated to be the most prevalent micronutrient deficiency globally, the most frequent cause of anemia. Our objective was to determine frequency of Iron Deficiency Anemia (IDA) among patients with $H$. Pylori gastritis.

Methods: It was a cross-sectional prospective study. Patients fulfilling inclusion criteria were enrolled at Liaquat National Hospital, Karachi, Pakistan. Blood samples were taken for serum iron, transferrin saturation, ferritin, and total iron-binding capacity and H.pylori assessed by urea breath test, stool for antigen, Rapid urease test or histopathology.

Results: 112 patients with $H$. Pylori infection with anemia were included. $53(47.3 \%)$ were males \& 59 $(52.7 \%)$ were females with mean age of $38.4464 \pm 9.00634$ years. Iron deficiency anemia was seen in 42 patients $(37.5 \%)$.

Conclusion: IDA was noted in $37.5 \%$ of cases. H. Pylori infection is a frequent cause of iron-deficiency anemia of previously unidentified origin among adults.
\end{abstract}

KEYWORDS: Helicobacter pylori infection, Iron deficiency anemia, Anemia.

How to cite this:

doi: https://doi.org/10.12669/pjms.37.3.3944

Rahat A, Kamani L. Frequency of iron deficiency anemia (IDA) among patients with Helicobacter pylori infection. Pak J Med Sci. 2021;37(3):776-781. doi: https://doi.org/10.12669/pjms.37.3.3944

This is an Open Access article distributed under the terms of the Creative Commons Attribution License (http://creativecommons.org/licenses/by/3.0), which permits unrestricted use, distribution, and reproduction in any medium, provided the original work is properly cited.

\section{INTRODUCTION}

1. Dr. Adeel Rahat, FCPS

Instructor,

Gastroenterology Section,

Aga Khan University Hospital,

Karachi, Pakistan.

2. Dr. Lubna Kamani FCPS, MRCP (UK), FRCP(London), FACG

Associate Professor and Director GI Residency Program,

Gastroenterology Department,

Liaquat National Hospital,

Karachi, Pakistan.

Correspondence:

Dr. Lubna Kamani FCPS, MRCP(UK), FRCP(London), FACG Associate Professor and Director GI Residency Program,

Gastroenterology Department,

Liaquat National Hospital,

Karachi, Pakistan.

Email: lkamani@yahoo.com

* Received for Publication:

November 26, 2020

* Accepted for Publication:

January 11,2021
H. Pylori is a chronic microbial infection, which is highly prevalent around the globe, especially in developing countries. The worldwide prevalence of H. Pylori is recorded to be about $50 \%$. Though high variation has been associated with age, geography, and socioeconomic status, its overall prevalence is high in developing countries due to many reasons. ${ }^{1}$

H. Pylori infection affects people from all across the globe but its prevalence differs from one region to the other. ${ }^{1}$ Usually acquired in childhood in the early stages, it can become chronic if untreated. ${ }^{2}$ The people who acquire this infection mostly do not show many symptoms, which leads to the hypothesis that some of $H$. Pylori strains are not harmful or even beneficial ${ }^{3}$ and may lead to illness in a very small number of adults. ${ }^{4}$ It can be a causative factor for multiple upper gastrointestinal 
diseases like gastritis, gastric, or duodenal ulceration, and it even augments the risk for gastric malignancy. ${ }^{5}$ As per the study conducted by Ford AC et al about the epidemiological aspects of $H$. Pylori, and the implications it has on public health; the important risk factors proposed for infection include growing age, shorter height, male sex, obesity, tobacco usage, poor socioeconomic conditions and low educational standing of the parents in studies conducted among children. ${ }^{6}$ Multiple diagnostic modalities are available with varying sensitivity and specificity for assessing H. Pylori infection. These include serology, urea breath test (UBT), Rapid Urease Test (RUT), biopsy with histopathology, and cultures. The most specific way remains the isolation of the microbe from gastric biopsies to establish the diagnosis of infection. Rasool et al conducted a study in 2007 which showed that $H$. Pylori was diagnosed by rapid urease test and histology in $61(65 \%)$ and 66 (70\%) patients respectively, while 14C UBT helped diagnosing infection in $63(67 \%)$ patients. UBT's accuracy was found to be $93 \%$ in comparison with histology with a high positive predictive value of $97 \%$ and the negative predictive value was $84 \%{ }^{7}$

Anemia, described as a reduction in the quantity of red blood cells (RBCs) or the quantity of hemoglobin $(\mathrm{Hb})$ concentration below established cut-off levels, is an international public health issue. According to the World Health Organization Database on Anemia (19932005), almost a quarter of the world's population is anemic. ${ }^{8}$ H. pylori infection (active state) was independently related to iron deficiency and the resultant anemia ${ }^{9}$ and there are also studies showing a poor response of anemia to oral iron replacement with coexistent active $H$. Pylori infection. ${ }^{10}$ Valiyaveetil et al conducted a randomized control study in 2004 that suggested that treatment of $H$. Pylori infection may lead to enhancement of response to oral iron therapy. ${ }^{10}$ Eradicating $H$. Pylori results in an enhanced response to oral iron replacement among infected pregnant female patients having Iron deficiency anemia. ${ }^{11}$

This study evaluated the frequency of IDA among anemic patients with $H$. Pylori infection. Multiple studies point toward a positive linkage between $H$. Pylori infection and anemia secondary to iron deficiency. ${ }^{12-14}$ However, the evidence is still insufficient in a Pakistani population. The results of this study will aid the clinicians in identifying patients who are at increased risk of developing anemia secondary to iron deficiency. Its early detection and proper management will, hence, save the patients from anemic heart failure, which happens to be a complication for chronic anemia. This will also upgrade the lifestyle of patients by improving the signs and symptoms of anemia like lethargy and easy fatigability.

\section{METHODS}

Adopting the cross-sectional approach, this study was conducted after hospital ethics committee approval (Ref: App\#0486-2019-LNH-ERC, Dated: June 3, 2019) at Liaquat National Hospital, Karachi in the Department of Gastroenterology, from July $29^{\text {th }}, 2019$ till Jan $28^{\text {th }}, 2020$. Patients that were enrolled were the ones attending the in-patient or out-patient facilities at the Gastroenterology Department at Liaquat National Hospital, Karachi with presence of H.pylori antigen in stool test or positive urea breath test or chronic gastritis because of $H$. Pylori on endoscopy \& gastric biopsy with anemia. For all patients included in this study, the following information were collected: age, gender, nutritional history and menstrual history in female patients. Patients were excluded if they had any other source of chronic blood loss. Blood samples were collected for calculating serum iron and ferritin concentrations, transferrin saturation, and total iron-binding capacity (TIBC). Patients were labeled having Iron Deficiency Anemia when the concentration of hemoglobin was less than 12 $\mathrm{g} / \mathrm{dl}$ in males and less than $11 \mathrm{~g} / \mathrm{dL}$ in females, and further serum studies showed a ferritin level of $<30 \mathrm{ng} / \mathrm{ml}$ with a raised Total Iron Binding Capacity greater than $450 \mu \mathrm{g} / \mathrm{dL}$, Serum Iron Level less than $50 \mu \mathrm{g} / \mathrm{dL}$, reduced transferrin saturation less than $20 \%$. Clinical history along with demographics were recorded by a principal investigator as per the predesigned pro forma, and a documented informed consent was attained ahead of enrolling the patient for the study. To avoid confounding variables, strict adherence was done to the inclusion and exclusion criteria.

Statistical analysis: For data analysis, SPSS version 22 was utilized. Percentages and frequencies were recorded for categorical variables like gender, education level, socioeconomic status, hemoglobin levels, and other parameters like serum Iron, Ferritin, transferrin saturation, and TIBC levels, iron deficiency anemia. Values were calculated as mean \pm standard deviation for continuous variables such as age. Effect modifiers like age, gender, education level, socioeconomic status, $\mathrm{Hb}$ 


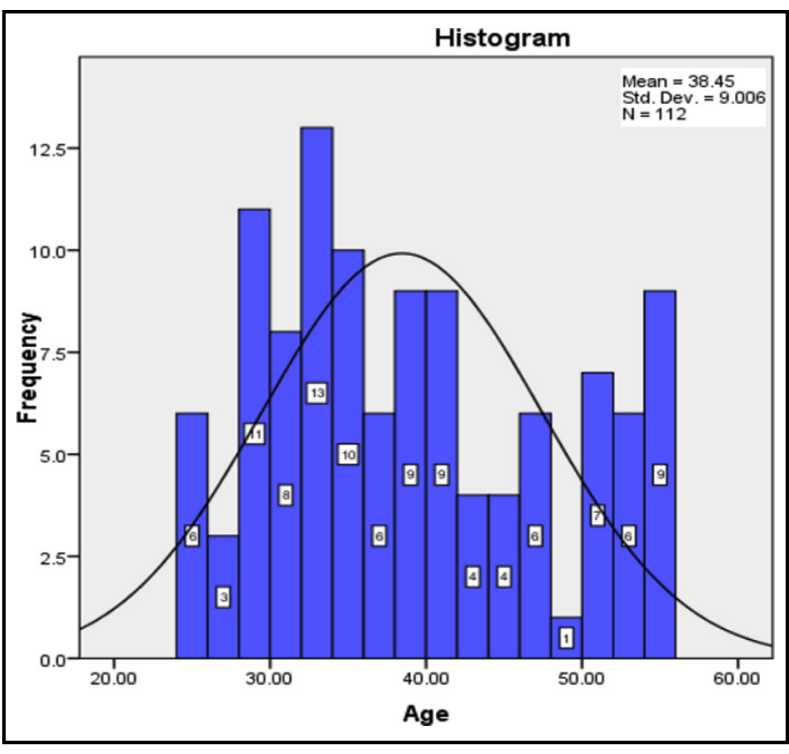

Graph-1: Frequency distribution of Age (years).

level were addressed via stratification. Chi-square test was applied. $\mathrm{P} \leq 0.05$ was considered as level of significance.

\section{RESULTS}

Total of 112 patients infected with H. Pylori with anemia were registered for this study. The mean age of $38.4464 \pm 9.00634$ years was observed. Age distribution is shown in Graph-1. The descriptive statistics in relation to age is shown in Table-I.

The mean hemoglobin level was $10.2188 \pm$ $0.76164 \mathrm{~g} / \mathrm{dl}$. The mean serum iron level was $52.633 \pm 15.289 \mathrm{ug} / \mathrm{dl}$.. The mean serum ferritin level was $125.8929 \pm 78.69777 \mathrm{ng}$ per $\mathrm{ml}$. The mean total iron-binding capacity was $285.4911 \pm$ $150.78916 \mathrm{ug} / \mathrm{dl}$.

The mean transferrin saturation was 25.9603 $\pm 14.71376 \%$. The descriptive statistics of socioeconomic status, Hemoglobin levels, Serum Iron, Serum Ferritin, TIBC, and transferrin saturation are shown in Table-I.

Fifty three patients $(47.3 \%)$ were males \& 59 patients $(52.7 \%)$ were females (as shown in TableII). In this study education level was matriculation in 47 patients $(42 \%)$, intermediate in $35(31.3 \%)$, and graduation in $30(26.8 \%)$.Socioeconomic status/monthly income was $<10000$ in 2 patients $(1.8 \%), 10000-25000$ in $22(19.64 \%)$ and $>25000$ in $88(78.57 \%)$. Iron deficiency anemia was seen in 42 patients $(37.5 \%)$.

The frequencies of age groups, gender, education level, and socioeconomic status were calculated according to iron deficiency anemia.
Table- I: Descriptive statistics of age, Socioeconomic status, Hemoglobin level, Serum iron level, Serum ferritin level, Total iron-binding capacity \& Transferrin saturation.

\begin{tabular}{lc}
\hline Variable & $M E A N \pm S D$ \\
\hline Age (years) & $38.4464 \pm 9.00634$ \\
Socioeconomic status (rupees) & $42366.0714 \pm 23660.890$ \\
Hemoglobin level (g/dl) & $10.2188 \pm 0.76164$ \\
Serum iron level (ug/dl) & $52.633 \pm 15.289$ \\
Serum ferritin level (ng per ml) & $125.8929 \pm 78.69777$ \\
Total iron binding & $285.4911 \pm 150.78916$ \\
$\quad$ capacity (ug/dl) & \\
Transferrin saturation (\%) & $25.9603 \pm 14.71376$ \\
\hline
\end{tabular}

The results are shown in Table-III. In this study, anemia secondary to iron deficiency was significantly associated with age ( $\mathrm{p}$-value $=0.042)$, while no association was observed with gender,

Table-II: Frequency distribution of gender, education level, socioeconomic status, H.pylori detection method, iron deficiency anemia $(n=112)$.

\begin{tabular}{lcc}
\hline Gender & $\begin{array}{c}\text { Frequency } \\
(n)\end{array}$ & $\begin{array}{c}\text { Percentage } \\
(\%)\end{array}$ \\
\hline Male & 53 & $47.3 \%$ \\
Female & 59 & $52.7 \%$ \\
Total & 112 & $100 \%$ \\
\hline Education level & Frequency & Percentage \\
& $(n)$ & $(\%)$ \\
\hline Matriculation & 47 & $42 \%$ \\
Intermediate & 35 & $31.3 \%$ \\
Graduation & 30 & $26.8 \%$ \\
Total & 112 & $100 \%$ \\
\hline Socioeconomic status (rupees) & Frequency & Percentage \\
& $(n)$ & $(\%)$ \\
\hline$<10000$ & 2 & $1.8 \%$ \\
10000-25000 & 22 & $19.64 \%$ \\
$>$ 25000 & 88 & $78.57 \%$ \\
Total & 112 & $100 \%$ \\
\hline H.pylori detection method & Frequency & Percentage \\
& $(n)$ & $(\%)$ \\
\hline Stool for H.pylori Antigen & 22 & $19.6 \%$ \\
Urea Breath Test & 28 & $25 \%$ \\
Rapid Urease Test & 9 & $8 \%$ \\
Histopathology & 53 & $47.3 \%$ \\
\hline Iron deficiency anemia & Frequency & Percentage \\
& $(n)$ & $(\%)$ \\
\hline Yes & 42 & $37.5 \%$ \\
No & 70 & $62.5 \%$ \\
\hline
\end{tabular}


Table-III: Iron deficiency anemia according to Age, Gender, Education level \& Socioeconomic status.

\begin{tabular}{|c|c|c|c|c|}
\hline \multirow{2}{*}{ Age (years) } & \multicolumn{2}{|c|}{ Iron deficiency anemia } & \multirow{2}{*}{ Total } & \multirow{2}{*}{ P-Value } \\
\hline & Yes & No & & \\
\hline 25-40 Years & $22(19.64 \%)$ & $50(44.64 \%)$ & $72(64.3 \%)$ & \\
\hline 41-55 Years & $20(17.85 \%)$ & $20(17.85 \%)$ & $40(35.7 \%)$ & 0.042 \\
\hline Total & $42(37.5 \%)$ & $70(62.5 \%)$ & $112(100 \%)$ & \\
\hline \multirow{2}{*}{ Gender } & \multicolumn{2}{|c|}{ Iron deficiency anemia } & \multirow[b]{2}{*}{ Total } & \multirow{2}{*}{ P-Value } \\
\hline & Yes & No & & \\
\hline Male & $19(17 \%)$ & $34(30.4 \%)$ & $53(47.32 \%)$ & \\
\hline Female & $23(20.5 \%)$ & $36(32.1 \%)$ & $59(52.67 \%)$ & 0.732 \\
\hline Total & $42(37.5 \%)$ & $70(62.5 \%)$ & $112(100 \%)$ & \\
\hline \multirow{2}{*}{ Education level } & \multicolumn{2}{|c|}{ Iron deficiency anemia } & & \multirow{2}{*}{ P-Value } \\
\hline & Yes & No & Total & \\
\hline Matriculation & $16(14.3 \%)$ & $31(27.7 \%)$ & $47(41.96 \%)$ & \multirow{4}{*}{0.813} \\
\hline Intermediate & $14(12.5 \%)$ & $21(18.8 \%)$ & $35(31.25 \%)$ & \\
\hline Graduation & $12(10.7 \%)$ & $18(16.6 \%)$ & $30(26.78 \%)$ & \\
\hline Total & $42(37.5 \%)$ & $70(62.5 \%)$ & $112(100 \%)$ & \\
\hline \multirow{2}{*}{ Socioeconomic status } & \multicolumn{2}{|c|}{ Iron deficiency anemia } & & \multirow{2}{*}{ P-Value } \\
\hline & Yes & No & Total & \\
\hline$<10000$ & $1(0.9 \%)$ & $1(0.9 \%)$ & $2(1.8 \%)$ & \multirow{4}{*}{0.068} \\
\hline $10000-25000$ & $6(5.35 \%)$ & $16(14.28 \%)$ & $22(19.64 \%)$ & \\
\hline$>25000$ & $35(31.25 \%)$ & $53(47.32 \%)$ & $88(78.57 \%)$ & \\
\hline Total & $42(37.5 \%)$ & $70(62.5 \%)$ & $112(100 \%)$ & \\
\hline
\end{tabular}

educational level \& socioeconomic status with the $\mathrm{p}$-value of $0.732,0.813 \& 0.068$ respectively.

\section{DISCUSSION}

In this study, iron deficiency anemia was noted in 42 patients (37.5\%) with H. Pylori infection, as compared to results of the Monzón et $\mathrm{al}^{14}$ study, which had stated that $38 \%$ of the patients may have iron deficiency anemia due to H. pylori infection, it also suggests that $H$. pylori gastritis can be a common etiological reason for IDA among adult patients with iron deficiency/iron refractoriness among whom the routine work-up for diagnosing the cause of IDA yielded no obvious result. One previous study stated that a large proportion of patients having atrophic body gastritis also encounter IDA and out of these, $61 \%$ were diagnosed with H. Pylori infection. ${ }^{15}$ A Korean study on adolescents (n=937) showed positive seropositivity rate for $H$. Pylori with iron deficiency to be $35.3 \% .{ }^{16}$
In Monzón et al study, ${ }^{14}$ eradication of $H$. pylori was linked with resolution of IDA without any additional iron replacement therapies and a relapse-free period of approximately 24 months mean follow-up. These results support in favor of the association of $H$. pylori infection with iron deficiency anemia. The Objective Response (OR) of infection with $H$. pylori as the causative reason for IDA was as high as ten times in the second group as compared to the first one.

In this study IDA was noted in $17 \%$ male patients and $20.5 \%$ female patients as compared to an earlier study that reported Iron Deficiency Anemia's prevalence among dyspeptic patients to be $26.9 \%, 35.2 \%$ in men, and $64.8 \%$ in women. Anemia's prevalence among patients with $H$. Pylori gastritis was $30.9 \%$ and $22.5 \%$ among those who were not infected. ${ }^{12}$ Thus, a hypothesis was put forth that H. Pylori -association with anemia was a result of reduced iron absorption in the context of hypochlorhydria. ${ }^{13}$ 
The mean hemoglobin level in this study was $11.830 \pm 1.695 \mathrm{~g} / \mathrm{dl}$ and the mean transferrin saturation was $27.693 \pm 12.695 \%$. Patients having both, H. Pylori gastritis and Iron Deficiency Anemia are more prone to have corpus gastritis than those who have H. Pylori -infection but not anemia. ${ }^{15}$ Because of corpus gastritis, reduced gastric acid secretion and raised intragastric $\mathrm{pH}$ may ensue which results in impairment of iron absorption. ${ }^{15}$ However, gastric acid secretion may normalize after eradicating $H$. Pylori. Likewise, another significant consequence of $H$. Pylori gastritis that results in decreased absorption of iron is a decrease in gastric juice ascorbic acid concentration as ascorbic acid aids in iron absorption from the gut by its reduction into the ferrous form. ${ }^{17}$

Another method that has been hypothesized to understand the relation between iron deficiency and H. Pylori gastritis was iron uptake by the bacterium itself. Various microorganisms use iron as a growth factor and H. Pylori is one of them. It contains a 19-kDa iron-binding protein resembling ferritin and thus may play a pivotal role in storing excess iron by the H. Pylori. ${ }^{18}$

There is another possible mechanism that explains the reduced availability of iron which is seizing up of iron because of lactoferrin in the gastric mucosa. H. Pylori sequesters iron from human lactoferrin through a receptor-mediated mechanism ${ }^{19}$. It appears that the gastric mucosal lactoferrin secretion is affected by the H. Pylori ${ }^{20}$. Lactoferrin levels of the gastric wall are reported to be considerably higher in $H$. Pylori positive IDA patients than the persons who were not anemic and also negative for $H$. Pylori, non-anemic but positive for $H$. Pylori, and $H$. Pylori negative with IDA. This shows that lactoferrin possibly plays an important role in iron deficiency anemia. ${ }^{16}$

In this study, $52.7 \%$ of patients were females and IDA was predominant in the female gender. Results of the study of Monzón et $\mathrm{al}^{14}$ on premenopausal women disagree with earlier results of Annibale et $\mathrm{al}^{15}$. The reason was that they showed that $92 \%$ of the patients, mainly premenopausal females, recovered from anemia at one year of follow-up after H. Pylori eradication. The discrepancies have more to do with the definition of response.

There may be certain other factors that are responsible for iron deficiency anemia in otherwise healthy normal premenopausal females. These mainly include increased blood loss during menstrual flow, pregnancy induced higher iron demands, dietary insufficiency, and breastfeeding. ${ }^{21}$ Menstrual blood loss may be reduced by approximately $50 \%$ by hormonal contraceptive therapy. This may help in females with average or mildly above-average blood loss ${ }^{22}$. Monzón et $\mathrm{al}^{14}$ study showed that this therapy was also helpful in resolving IDA in those premenopausal females in whom the requirements of iron were increased despite of eradication of $H$. pylori.

H. pylori infection may also result in Latent Deficiency, which may improve after the infection has been irradicated ${ }^{23,24}$. However, it is not known if $H$. Pylori -infected patients who simultaneously have Latent Deficiency are at higher risk of having IDA or not.

In conclusion, the results of this current study show that $H$. pylori infection is a common cause of IDA among females and patients with lower education levels.

Limitation of the Study: The main limitations were relatively smaller sample size, and improvement in anemia following $H$. pylori eradication. So additional studies with larger sample sizes are suggested.

Acknowledgements: The authors would like to thank Dr Hamid Kalwar, Dr Tauqeer Sheikh and Dr Muhammad Asim for their support and help during compilation of this manuscript.

\section{Financial disclosures: None}

\section{Conflict of Interest: None}

\section{CONCLUSION}

Iron Deficiency Anemia (IDA) was noted in 37.5\% of cases. H. pylori infestation is a frequent cause of iron-deficiency anemia of previously unknown origin among adults.

\section{REFERENCE}

1. Hunt RH, Xiao SD, Megraud F, Leon-Barna R, Bazzoli F, Van der Merwe S, et al. World Gastroenterol Org (WGOOMGE) Clin Guide - Helicobacter pylori infection in developing countries. 2007;12(1):40-52.

2. Torres J, Perez-Perez G, Goodman KJ, Atherton JC, Gold BD, Harris PR, et al: A comprehensive review of the natural history of Helicobacter pylori infection in children. Arch Med Res. 2000;31(5):431-469

3. Mishra S. Is Helicobacter pylori good or bad?. Eur J Clin Microbiol Infec Dis. 2013;32(3):301-304.

4. Cover TL, Blaser MJ: Helicobacter pylori in health and disease. Gastroenterol. 2009;136:1863-73 
5. Testerman TL, Morris J. Beyond the stomach An update view of Helicobacter pylori pathogenesis, diagnosis, and treatment. World J Gastroenterol. 2014;20(36):1278112808. doi: 10.3748/wjg.v20.i36.12781

6. Ford AC, Axon ATR. Epidemiology of Helicobacter pylori infection and public health Implications. Helicobacter. 2010;15:1-6

7. Rasool S, Abid S, Jafri W. Validity and cost comparison of 14carbon urea breath test for diagnosis of H Pylori in dyspeptic patients. World J Gastroenteol. 2007;13(6):925.

8. World Health Organization. World prevalence of anemia 1993-2005. WHO Global Database on Anemia.World Health Organization; Web. 5 Dec 2014.

9. Baggett HC, Parkinson AJ, Muth PT, Gold BD, Gessner BD. Endemic iron deficiency associated with helicobacter pylori infection among school-aged children in Alaska. Pediatrics. 2006;117:396-404.

10. Valiyaveettil AN, Hamide A, Bobby Z, Krishnan R. Effect of anti-helicobacter pylori therapy on outcome of irondeficiency anemia, a randomized, controlled study. Ind J Gastroenterol. 2004;24(4):155-157.

11. Malik R, Guleria K, Kaur I, Sikka M, Radhakrishnan G. Effect of helicobacter pylori eradication therapy in iron deficiency anaemia of pregnancy-a pilot study. Indian J Med Res. 2011;134:224-231

12. Kibru D, Gelaw B, Alemu A, Addis Z. Helicobacter pylori infection and its association with anemia among adult dyspeptic patients attending Butajira Hospital, Ethiopia. BMC Inf Dis. 2014;14(1):1

13. Harris PR, Serrano CA, Villagrán A, Walker MM, Thomson M, Duarte I, et al. Helicobacter pylori-associated hypochlorhydria in children, and development of iron deficiency. J ClinPathol. 2013;66:343-347.

14. Monzón H, Forné $M$, Esteve $M$, Rosinach M, Loras C, Espinós JC, et al. Helicobacter pylori infection as a cause of iron deficiency anaemia of unknown origin. World J Gastroenterol: WJG. 2013;19(26):4166.

15. Annibale B, Capurso G, Martino G, Grossi C, Delle Fave G. Iron deficiency anaemia and helicobacter pylori infection. Int J Antimicrobial Agents. 2000;16(4):515-519.

16. DuBois S, Kearney DJ. Iron-deficiency anemia and helicobacter pylori infection: A review of the evidence. Am J Gastroenterol. 2005;100(2):453.
17. Atanassova BD, Tzatchev KN. Ascorbic acid-important for iron metabolism. Folia medica. 2008;50(4):11.

18. Doig P, Austin JW, Trust TJ: The Helicobacter pylori 19.6-kilodalton protein is an iron-containing protein resembling ferritin. J Bacteriol. 1993;61:2694-2697.

19. Husson MO, Legrand DO, Spik GE, Leclerc HE. Iron acquisition by Helicobacter pylori: importance of human lactoferrin. Infection and immunity. 1993;61(6):2694-2697.

20. Choe YH, Oh YJ, LEE NG, Imoto I, Adachi Y, Toyoda $\mathrm{N}$, Gabazza EC. Lactoferrin sequestration and its contribution to iron-deficiency anemia in Helicobacter pylori-infected gastric mucosa. J Gastroenterol Hepatol. 2003;18(8):980-985.

21. Sayer JM, Donnelly MT, Ching CK, Long RG. The aetiology of iron deficiency anaemia in pre-menopausal women. Gastroenterol. 1994;106:A26.

22. ESHRE Capri Workshop Group. Noncontraceptive health benefits of combined oral contraception. Hum Reprod Update. 2005;11:513-525

23. Nahon S, Patey-Mariaud DeSerre N, Lejeune O, Huchet FX, Lahmek P, Lesgourgues B, Traissac L, Bodiguel V, Adotti F, Tuszynski T, et al. Duodenal intraepithelial lymphocytosis during Helicobacter pylori infection is reduced by antibiotic treatment. Histopathology. 2006;48:417-423

24. Rosinach M, Esteve M, González C, Temiño R, Mariné M, Monzón H, Sainz E, Loras C, Espinós JC, Forné $\mathrm{M}$, et al. Lymphocytic duodenosis: aetiology and long-term response to specific treatment. Dig Liver Dis. 2012;44:643-648

\section{Author's Contributions:}

AR: Data collection and entry, statistical analysis, writing of first draft.

LK: Conceived the idea, Statistical analysis, critical revision of manuscript and is responsible for the integrity of the study. 